\title{
Determinants of Peptic Ulcer Disease: A Systematic Review
}

\author{
Kainat Sadiq ${ }^{1}$, Bahisht Rizwan ${ }^{2}$, Sana Noreen ${ }^{2 *}$, Arooj Fatima ${ }^{1}$, Minal Sheraz ${ }^{1}$, Momina Shafqat ${ }^{1}$, Hafiza Mehak Rashid ${ }^{1}$ \\ ${ }^{1}$ Students at University Institute of Diet and Nutritional Sciences, the University of Lahore, Pakistan \\ ${ }^{2}$ Senior Lecturer at University Institute of Diet and Nutritional Sciences, Faculty of Allied Health Sciences, the University of Lahore,
} Pakistan

\author{
Article History \\ Received: 28.08.2020 \\ Accepted: 18.09.2020 \\ Published: 12.10 .2020 \\ Journal homepage:
}

https://www.easpublisher.com/easjnfs

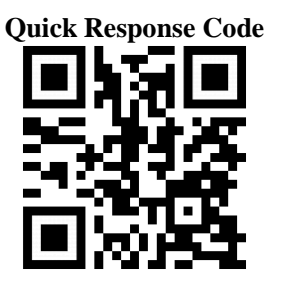

Abstract: Peptic ulcer is in the study for centuries. A peptic ulcer is the formation of sores and ulcer in the stomach and duodenum. The two main types of peptic ulcer are gastric ulcer and duodenum ulcer. It is the multifactorial health problem in the past century; its popularity and risk factors have changed a lot. The population is suffering from a peptic ulcer is about $4 \%$. About $10 \%$ is the risk in the duration of a person life. To aim at the different risk factors of peptic ulcers in this systematic review with reference to the literature. Medlin, Embase, Science Direct, Google Scholar, and books were used to collect the data. Data were collected from studies published between 2015-2020, and the studies published before 2015 were excluded. Studies were reviewed manually by their abstract and by full text. H pylori and the use of NSAIDs are the main risk factors for developing peptic ulcer disease. Studies showed that the risk of peptic ulcer disease is double in the people with these risk factors. The result of this review concluded that the administration of all these risk factors contributes to the increase in the number and severity of peptic ulcers. According to the results, by overcoming all these risk factors and improving our health and living standards, this disease can be cured.

Keywords: Peptic Ulcer Disease, H. Pylori, Non-Steroidal Anti-inflammatory Drugs NSAIDs, Obesity.

Copyright (C) 2020 The Author(s): This is an open-access article distributed under the terms of the Creative Commons Attribution 4.0 International License (CC BY-NC 4.0) which permits unrestricted use, distribution, and reproduction in any medium for non-commercial use provided the original author and source are credited.

\section{INTRODUCTION}

Peptic ulcer is a severe upper gastrointestinal mucosal layer disorder. This layer passes through the deeper layer of the intestine wall [1]. Peptic ulcers refer to the ulcer that occurs due to the breakdown of these restorative mechanisms and normal defence [2]. generally, more than one system may be malfunctioning for the production of symptomatic peptic ulcers. Peptic ulcers usually display signs of persistent inflammation and healing mechanisms affecting the lesion [3]. Peptic ulcer disease (PUD) is a mucosa infection that exceeds the muscular mucosa of the stomach or duodenum. PUD follows stomach mucosal wounds due to the difference between defensive and aggressive mucosal issues [4]. The number of people with Helicobacter pylori infections in western countries is approximately proportional to their age (i.e., $20 \%$ at the age of $20,30 \%$ at $30.80 \%$ at 80 years old). Prevalence in developing countries is higher and is estimated at $70 \%$, while in developed countries, the ratio is a maximum of $40 \%$ [5].

Peptic Ulcer Disease etiology includes infection with H. Pylori bacteria, smoking and alcohol, pepsin, stress, NSAIDS, bile acids, steroids, and gastric mucin (genetic) [6,7]. Many reasons comprise Behcet Disorder, Zollinger Ellison Syndrome, Liver Cirrhosis,
Crohn Disease, and related signs of coronary heart failure, stomach cancer and enlargement of the stomach lining or gallbladder [8]. Significant signs of Peptic Ulcer Disease are non-specific and history-independent, recurrent signs comprising epigastric discomfort, diarrhoea, flatulence, bloating, nausea, heartburn, a posterior ulcer can trigger pain in back, and symptoms are eased by antacid [9]. Peptic ulcers are asymptomatic in some instances. Complications of haemorrhage and perforation considerably lead to the morbidity and death of peptic ulcers. Ulcers may perforate through the peritoneal cavity or invade the associated organ (usually the pancreas) or erode the artery and induce severe haemorrhage. Melena referred to as black tarry stools, is a common finding linked with peptic ulcer disease in older adults. Melena may indicate either acute or chronic GI bleeding [10]. Diagnosis is primarily based on typical signs, endoscopies, barium comparison, and H-Pylori infection tests [11]. PUD prediction is outstanding if the root reason is one as $\mathrm{H}$. Infection of pylori or medications may be treated [12]. In light of the application of eradication treatment with Infection of Pylori and proton-pump inhibitors (PPIs) and improved endoscopic treatment solutions developed in recent decades, PUD-associated mortality has not declined at the same period as incidence [13]. 
H. pylori infection, gastritis, the usage of aspirin and other NSAIDs, corticosteroids, and stress (so-called stress-inducing ulcers) are the primary causes of peptic ulcers. Many factors are involved in developing PUD, which are the most outstanding environmental factors, including the psychosocial condition, which is stress. Stress influences the functioning of the gastrointestinal tract, moreover through long-term or short-term effects [14]. Experiments have confirmed that stress leads to the development of PUD and is also used to generate PUD concluded laboratory animal models [15]. In the short or long-term, stress affects the function of the gastrointestinal tract; studies have reported that stress helps to form PUD and is frequently used to make PUD in experimental animal models [15]. Stresses, obesity, unhealthy diet, H. Pylori, NSAIDS are some of the risk factors for peptic ulcers and widely used medications containing a small aspirin level. Males are known to be the most influenced when it comes to sex. Peptic ulcer condition usually has no noticeable signs, although it may be identified by swelling, perforation, and gastric outlet blocking. It can be identified by endoscopy screening. The occurrence of Pylori infection in developed countries is higher among citizens belonging to a low socioeconomic community. However, the overall frequency rate is declining because people are improving their living standards and migrating from rural to urban areas [16].

Tobacco products are used to reduce the secretion of bicarbonate, decrease the flow of mucous blood, exacerbate inflammation, and be associated with further $\mathrm{H}$. Pylori infection complications. Nicotine present in smoke stimulates gastric acid production. Hence smoking is considered a risk cause for peptic ulcer disease [17]. Dietary factors caffeinated food, spicy, fried food, dietary polyphenols like (gallic acid. Curcumin, grape, pomegranate, ellagic acid, green tea, allylpyrocatechol, etc.). Smoking and alcohol are hazardous factors. Chronic alcohol impairs the gastric mucosal barrier by inhibiting COX 1 receptor enzymes that reduce cytoprotective prostaglandin production. Smoking causes a decrease in the circulation of the epidermal factor and increases the gastric mucosa's free production. However, some studies have found a link between smoking and ulcers. Studies have initiated that drinking alcohol raises the risk when it is related to $\mathrm{H}$ infection. Pylori appear to be self-limiting. Although combined with $\mathrm{H}$ pylori infection, the rise is modest compared to the high-risk component. A peptic ulcer is one of the serious medical and health problems in Pakistan. This disease is predominantly affecting both younger and older age group [18]. Due to lack of awareness and knowledge about dietary practices in the people are regarding risk factors of the disease may be led to an increase of this disease. Thus, this review aims to promote PUD prevention through established risk factors. This systematic review identifies the recent research on the risk aspects of PUD.

\section{Methodology}

The present review was performed from August to September 2018 in compliance with the preferred reporting items for systematic reviews and meta-analyses (PRISMA) declaration standards for Systematic Reviews. We also studied the entire range of topics on peptic ulcers for instance biology, etiology, pathology, epidemiology, psychology, and anatomy, and neurology, bacterial and clinical research.

\section{Search strategy and study selection}

To achieve this aim, we have researched, reviewed articles and reports published during the past five years, Medlin, Embase, Science Direct and Google Scholar, Science Direct. Books published on peptic ulcers and the pathogenesis of disease was also included. Searching was done constraints of the English language. The time was from the earliest available publication until 1 January 2015. Collected data on the research date, study design, and the primary outcome of peptic ulcers. The selected researches were summarized, and then non-reproducible researches were omitted. The collected details were displayed in Table 1 .

\section{INCLUSION CRITERIA}

Inclusion criteria included participants diagnosed with peptic ulcer disease, including gastric ulcer or duodenal ulcer; 10 to 70 years of age; both genders, healthy and asymptomatic. The eligible studies should analyze the risk factors of peptic ulcer.

\section{ExCLUSion Criteria}

Factors of Risk have not been examined, and complete text could not be accessed. Other conditions, including gastroenteritis, gastritis, gastroparesis, gastric cancer, and malignancies, were exclusion criteria.

\section{Data Collection}

The following details were derived from each study: Author, year of publication; study design; total number of assessed participants; their peptic ulcer risk factors.

\section{Data EXTRACTION AND ANALYSIS}

Information concerning the systematic review question elements was extracted from the research and collated in qualitative tables. A specific review of Peptic Ulcer Disease experiments is performed with great care as various sampling approaches provide an outline. 


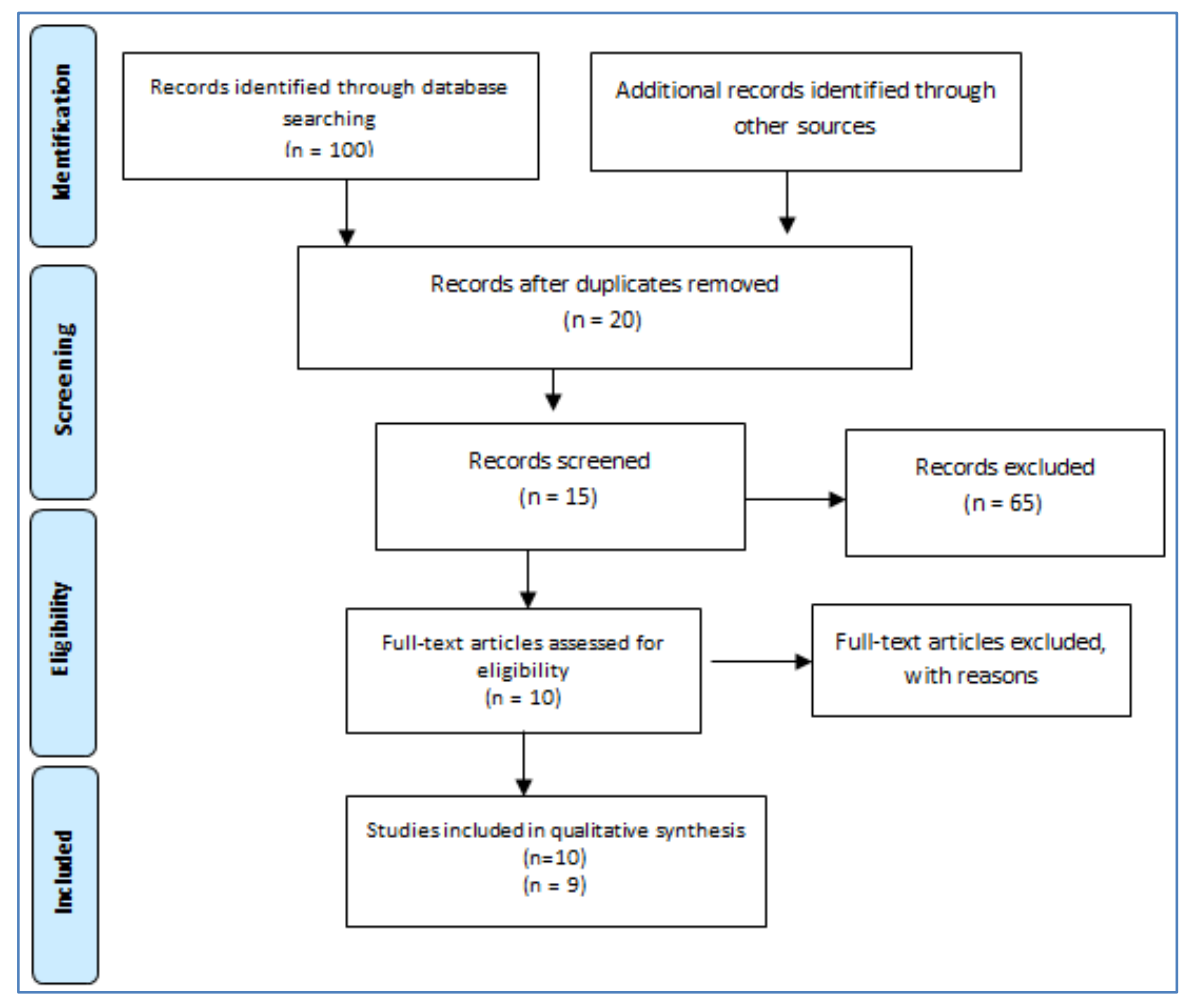

Fig-1: PRIMA flowchart of study selection

\section{Study Selection Process}

Figure 1 details the study selection process and the number of articles retrieved and excluded at each stage. Of the 100 studies retrieved, 20 were excluded as duplicated, 65 were excluded as having no access to full text to a manuscript, most commonly because the studies examined peptic ulcer disease along with its risk factors were only included. Five papers were also omitted if their study topic was irrelevant or did not report any relevant information. Ten papers are selected for recent data selection.

\section{RESULTS}

Table-1: Determinants of peptic Ulcer

\begin{tabular}{|c|c|c|c|c|c|}
\hline Author \& Year & $\begin{array}{c}\text { Sample } \\
\text { Size }\end{array}$ & Study design & Risk factor & Outcomes/findings & Reference \\
\hline $\begin{array}{l}\text { Ulrik Deding - } \\
(2016)\end{array}$ & $\mathrm{n}=17,525$ & Cohort study & Stress & $\begin{array}{l}\text { An aggregate of } 35,700 \text { individuals got the health-related } \\
\text { questionnaires, of which } 12,308 \text { did not reply. } 1550 \text { individuals } \\
\text { did not answer all PSS- } 10 \text { things and were consequently } \\
\text { avoided. Before the benchmark, } 13 \text { individuals were enlisted as } \\
\text { dead and were avoided. Due to a lack of covariate data for } \\
\text { complete model adjustment, a total of } 4,304 \text { were excluded. The } \\
\text { all outnumber of outstanding examples is } 17,525 \text {. During the } \\
\text { subsequent period, } 121 \text { instances of clear peptic ulcer were } \\
\text { recorded. } 75 \text { individuals got triple treatment, and } 72 \text { individuals } \\
\text { were determined to have a peptic ulcer in the clinic ( } 26 \text { of them } \\
\text { were dealt with and analyzed). }\end{array}$ & 19 \\
\hline $\begin{array}{l}\text { Young bok lee - } \\
\text { August (2017) }\end{array}$ & $\mathrm{n}=13,453$ & $\begin{array}{l}\text { Population- } \\
\text { based study }\end{array}$ & Stress & $\begin{array}{l}\text { Out of 14,266 participants, } 813 \text { were reported to have been } \\
\text { diagnosed with PUD, with a } 5.7 \% \text { prevalence. Compared with } \\
\text { the non-PUD group, the PUD group was significantly older and } \\
\text { mostly male. Subjects with PUD have a higher current history of } \\
\text { smoking and heavy drinking habits. They are more likely to } \\
\text { have other comorbidities, such as diabetes, hypertension, and } \\
\text { metabolic syndrome than non-ulcer subjects. There were also } \\
\text { significant differences in the education level and income of the } \\
\text { lowest quantile of subjects who received or did not receive } \\
\text { PUD. }\end{array}$ & 20 \\
\hline $\begin{array}{l}\text { Aust } \quad \text { prescr } \\
(2017)\end{array}$ & $\mathrm{n}=57000$ & $\begin{array}{l}\text { Experimental } \\
\text { study }\end{array}$ & NSAIDs & $\begin{array}{l}57000 \text { patients were examined with the dose of aspirin and other } \\
\text { NSAIDs. It was evident that the patients who take non- } \\
\text { inflammatory drugs are more vulnerable to have gastrointestinal } \\
\text { problems, including peptic ulcer and GI bleeding. People with a } \\
\text { history of peptic ulcers or other gastrointestinal problems are } \\
\text { more vulnerable to the GI tract's toxicity. COX-2 inhibitor is }\end{array}$ & 21 \\
\hline
\end{tabular}




\begin{tabular}{|c|c|c|c|c|c|}
\hline & & & & $\begin{array}{l}\text { well known to treat the toxicity caused by the abnormal doses of } \\
\text { non-inflammatory drugs. The dose should be given carefully } \\
\text { before prescribing the NSAIDs to any patient, known as proton } \\
\text { pump therapy, should be done to know the intensity of GI } \\
\text { infection. }\end{array}$ & \\
\hline $\begin{array}{l}\text { Murtaza } \\
\text { Mustafa, } \\
\text { jayarum menon, } \\
\text { RK Muiandy, R. } \\
\text { Fredie, MM } \\
\text { Sein, A. Fariz } \\
\text { (2015) }\end{array}$ & $\mathrm{n}=32,7000$ & $\begin{array}{l}\text { Population- } \\
\text { based study }\end{array}$ & $\begin{array}{l}\text { H. Pylori, } \\
\text { NSAIDs, } \\
\text { Smoking, } \\
\text { Alcohol }\end{array}$ & $\begin{array}{l}\text { A sample size of } 32,7000 \text { people was examined, and } 301,000 \\
\text { deaths were reported due to these risk factors. Collectively, all } \\
\text { the risk factors cause GI infections like a peptic ulcer. However, } \\
\text { the most common factors are NSAIDs, and H. Pylori bacteria } \\
\text { are specifically associated with the peptic ulcer that harms the } \\
\text { GI tract. On the other hand, people who take NSAIDs are } \\
\text { getting more prune for the disease due to reducing the therapy } \\
\text { proton pump inhibitor. Smoking and alcohol make the condition } \\
\text { worst by inhibiting the COX-2 inhibitor, which is cytoprotective } \\
\text { and help with the dealing of NSAIDs toxicity }\end{array}$ & 22 \\
\hline Eryati Darwin & $\mathrm{n}=40$ & $\begin{array}{l}\text { Cross- } \\
\text { sectional study }\end{array}$ & $\begin{array}{l}\text { H.pylori, } \\
\text { stress }\end{array}$ & $\begin{array}{l}\text { A cross-sectional study with } 40 \text { patients with stomach disorders, } \\
\text { the average age of } 37 \text { years old divided into two groups (stress } \\
\text { vs non-stress), the cortisol level in both groups was different. } \\
\text { Furthermore, the observation in this study was that the risk of } \\
\text { infection is higher in the stressed group as compared to the non- } \\
\text { stressed group. }\end{array}$ & 23 \\
\hline M.Zamani & $\mathrm{n}=14056$ & $\begin{array}{l}\text { Cross- } \\
\text { sectional study }\end{array}$ & H.pylori & $\begin{array}{l}\text { A sum of } 14056 \text { records was acquired at first. In the wake of } \\
\text { applying avoidance standards in a few stages, } 183 \text { examinations } \\
\text { were chosen. An investigation of } 410,879 \text { members from } 73 \\
\text { nations/areas on six mainland demonstrated that the worldwide } \\
\text { predominance rate was } 44.3 \% \text { ( } 95 \% \text { CI: } 40.9-47.7) \text {. The extent } \\
\text { in creating nations is } 50.8 \% \text { ( } 95 \% \text { CI: } 46.8-54.7) \text {, while that in } \\
\text { created nations is } 34.7 \% \text { ( } 95 \% \text { CI: } 30.2-39.3) \text {. The worldwide } \\
\text { Helicobacter pylori disease rate for ladies is } 42.7 \% \text { (95\% CI: } 39- \\
46.5 \text { ), while that for men is } 46.3 \% \text { ( } 95 \% \text { CI: } 42.1-50.5) \text {. The } \\
\text { commonness of grown-ups ( } \geq 18 \text { years old) was altogether } \\
\text { higher than that of youngsters ( } 48.6 \% \text { [95\% CI: } 43.8-53.5] \text { and } \\
32.6 \% \text { [ } 95 \% \text { CI: } 28.4-36.8] \text {, separately). Contrasted with the } \\
\text { period from } 2000 \text { with } 2009 \text {, the pervasiveness rate from } 2009 \\
\text { to } 2016 \text { did not diminish measurably. }\end{array}$ & 24 \\
\hline $\begin{array}{l}\text { Jeung Hui Pyo, } \\
\text { Hyuk Lee (2019) }\end{array}$ & $\mathrm{n}=32,472$ & Cohort study & Obesity & $\begin{array}{l}\text { The sample size of } 32,472 \text { people is examined due to this risk } \\
\text { factor obesity. Design of this study is the Cohort. In this large } \\
\text { group, the hazard of having a PUD did not increase directly in } \\
\text { overweight people or MHO people linked to the general } \\
\text { population. These results deliver compelling evidence } \\
\text { comparing with previous studies. Though, the previously } \\
\text { described relationship between obesity and PUD looks to be due } \\
\text { to a combination of issues, including various lifestyle issues or } \\
\text { metabolic syndrome. Other forensic investigations confirm } \\
\text { confirming these results. }\end{array}$ & 25 \\
\hline $\begin{array}{l}\text { Aghareed M. } \\
\text { Asali1, } \\
\text { Mohammed A. } \\
\text { Alghamdi (2018) }\end{array}$ & $\begin{array}{l}\text { Smoking } \\
\mathrm{n}=2416\end{array}$ & Random study & $\begin{array}{l}\text { Smoking } \\
\text { and alcohol } \\
\text { H. pylori } \\
\text { NSAIDs }\end{array}$ & $\begin{array}{l}\text { In smoking, we examine } 2416 \text { patients and on the other side } \\
1500 \text { people for alcohol, and this was a casual study which } \\
\text { clears that H. pylori and the use of NSAIDs are the maximum } \\
\text { common components of PUD formation, and genetics, stress, } \\
\text { and comorbidity raise the risk of PDU development. Job stress } \\
\text { in the medical field plays a major role as a risk of emerging } \\
\text { PUD. Therefore, effective elimination and preclusion of harmful } \\
\text { ones should be done to avoid PUD's occurrence and is a } \\
\text { problem. }\end{array}$ & 26 \\
\hline $\begin{array}{l}\text { Sang pyo lee, } \\
\text { In-kyumg sung, } \\
\text { jeong Huwan } \\
\text { kim, sun young } \\
\text { lee, hyung seok } \\
\text { park, chan sup } \\
\text { shim } \\
(2015)\end{array}$ & $\mathrm{n}=23,698$ & $\begin{array}{l}\text { Experimental } \\
\text { study }\end{array}$ & $\begin{array}{l}\text { Stress and } \\
\text { depression }\end{array}$ & $\begin{array}{l}\text { Stress and depression is the main cause for demolishing the } \\
\text { mental abilities, and hence it affects the digestive system also. } \\
\text { With the decrease in mental abilities, the functions of the GI } \\
\text { tract starts getting diminished, which causes several digestive } \\
\text { problems like PUD and many other forms of ulcers. These risk } \\
\text { factors associates with the other common factors and causes } \\
\text { defects in the GI tract that can cause the internal and external } \\
\text { bleeding }\end{array}$ & 27 \\
\hline $\begin{array}{l}\text { Young bok lee, } \\
\text { jhan yu MD, } \\
\text { Hyun ho choi, } \\
\text { sung soo kim } \\
\text { MD, yung gyu } \\
\text { park, hyun suk } \\
\text { chae } \\
(2017)\end{array}$ & $\mathrm{n}=24,871$ & $\begin{array}{l}\text { Population- } \\
\text { based study }\end{array}$ & $\begin{array}{l}\text { Stress and } \\
\text { mental } \\
\text { illness }\end{array}$ & $\begin{array}{l}\text { Young children of age round about } 19 \text { and } 20 \text { were examined, } \\
\text { which shows the signs of mental illness, including stress and } \\
\text { depression, and became more the victim of digestive disorders } \\
\text { like PUD. Mental health is the leading problem among the } \\
\text { children of the modern age, and they show the dysfunction of } \\
\text { many internal organs that are causing these kinds of disorders. } \\
\text { Hence mental illness is becoming a risk factor for PUD, } \\
\text { especially in children }\end{array}$ & 28 \\
\hline
\end{tabular}




\section{DISCUSSION}

The primary aim of this report was to establish risk factors contributing to the incidence of PUD, with specific risk factors - reasons for PUD include H Pylori infection, NSAIDs. Less prominent risk factors include caffeine, smoking, narcotics, chronic cancer, neurological disorders, radiation, and Crohn disease. In this population-based investigation, we found a strong connection between PUD and psychological well-being issues, (for example, serious pressure, discouraged disposition, and self-destructive ideation). PUD patients are more inclined to mental issues. Regardless of whether changes are made for other notable danger factors, for example, age, sexual orientation, smoking, liquor utilization, low financial status, and metabolic sicknesses, mental issues are firmly identified with PUD's history. In a few past investigations, PUD advancement's conceivable neurotic component because of emotional well-being issues has been proposed [16].

To begin with, the gastrointestinal framework and the mind are firmly associated through the autonomic sensory system (the cerebrum gut hub). On account of pressure or wretchedness, the sensory system might be upset, which may expand the discharge of pepsin and gastric corrosive and cause mucosal harm. Second, mental issues may adjust the emission of cortisol by influencing the hypothalamic-pituitaryadrenal pivot. Cortisol levels normally ascend under unpleasant conditions, which may prompt expanded degrees of corrosive gastric discharge. Raised degrees of cortisol and gastric corrosive may prevent the ordinary incendiary reaction of the gastrointestinal lot. Third, discouraged individuals are more averse to get treatment for gentle dyspepsia brought about by gastritis or duodenitis, so their condition might be bound to form into PUD. Fourth, smoking and drinking are more normal among individuals with psychological wellness issues. Smoking advances the creation of free radicals and instigates vasoconstrictors to influence mucosal bloodstream. In any case, results show that subsequent to modifying for the impacts of smoking and drinking, mental issues are identified with the improvement of PUD [27].

This populace based investigation has a few restrictions. The exploration configuration is crosssectional, so it cannot uphold charges of causality. Incapable of deciding if PUD is the reason or outcome of mental issues. So also, the medications and family background of PUD in each subject were not accessible in the informational index. We cannot inspect the impacts of gastrointestinal medications, for example, proton siphon inhibitors or $\mathrm{H} 2$ receptor blockers. Second, South Korea has a high pace of Helicobacter pylori disease. Nonetheless, this examination did exclude the identification of Helicobacter pylori. Accordingly, relationship or disarray due to Helicobacter pylori disease cannot be precluded. Third, in spite of the fact that endoscopy is generally required for affirmation, PUD is resolved on the doctor's past determination in this examination. As per reports, the rate of PUD affirmed by endoscopy in Korea is 2.45 $7.0 \%$, reliable with our outcomes [28].

Furthermore, since the lifetime screening rate for gastric malignant growth during the investigation time frame was roughly $65 \%$, we accept that a large portion of the subjects in this examination has been determined to have PUD through endoscopy. Upper gastrointestinal endoscopes are promptly accessible in South Korea at a low cost or given to free during the biennial government wellbeing check or yearly representative wellbeing check. Along these lines, PUD analyzed as self-detailed by a specialist is viewed as dependable information. Regardless of these restrictions, this investigation despite everything has critical preferences since it is a populace based examination with an example illustrative of the whole Korean populace. Like this, the aftereffects of this examination can be applied to all infections and states of mind of Koreans. The investigation additionally included subjects who announced whether they felt pushed or discouraged in their day by day lives, not restricted to clinicians determined to have psychological maladjustment. Hence, this investigation included numerous individuals who had emotional well-being issues; however, did not really go to a psychological facility [29].

To put it, psychological wellness issues, for example, stress, wretchedness, and self-destructive thoughts are firmly identified with PUD. These mental issues were discovered to be identified with PUD. Individuals who are under extreme pressure or wretchedness might be more vulnerable to PUD. Along these lines, specialists should give close consideration to the cozy connection between PUD commonness and mental problems [29].

In this experimentally based study, researchers found that the people who are having several risk factors are more vulnerable to gastrointestinal infections like a peptic ulcer. If a person is taking NSAIDs for a reason, it can be toxic for several risk factors. These include the increased age ( $>65$ years), history of peptic ulcer, and heart diseases. The patients with these risk factors are more vulnerable and have $9 \%$ more chances to get NSAIDs toxicity, which leads to the peptic ulcer and GI bleeding. However, NSAIDs should not be given without therapy, and alternatives should be prescribed instead. Some NSAIDs are harmful, like COX-2 inhibitors, ibuprofen, naproxen, associated with the GI infection, but the risk varies between them. In some cases like heart diseases, patients are prescribed low dose Aspirin to reduce the disease. However, it acts like an antiplatelet and anticoagulant drug, which leads to the GI tract's toxicity and, worst, the condition of the ulcers. $\mathrm{H}^{2}$ receptor antagonists also cause the effects to get worse but depend upon the doses. Researchers said 
that one dose daily could not help with the betterment, but the two doses can treat the gastrointestinal ulcers. Misoprostol can help with the reduction of GI problems like ulcers. It is found to cure the duodenal ulcers (53\%) and gastric ulcers (74\%). Proton pump inhibitor therapy is well known for the reduction of the gastric and duodenal ulcers, and before prescribing any kind of NSAIDs, this therapy should be done to reduce the GI toxicity [1].

In this study, researchers show several risk factors for gastrointestinal infections like ulcers and bleeding. Among all the factors, some are most commonly causing peptic ulcers that are getting worse and becoming the death of 30,1000 people out of 32,7000. These risk factors include H. Pylori bacteria, NSAIDs, smoking, and alcohol consumption. Among them, the H. Pylori and NSAIDs are the more common and leading causes of death among the patients of peptic ulcers. H. Pylori is the major causative factor of $60 \%$ of Gastritis and $45-50 \%$ of the ulcers. These bacteria cause the GI tract's inflammation due to which the immune system becomes weak, and it becomes difficult for it to remove the infection from the body. This bacteria survives and multiplies in the body under a suitable environment and harms the tract through the body. Most of the deaths occur due to these factors, and this is the leading cause of ulcers. On the second number, the most dangerous and common causative agent is NSAIDs. It is clear that after the H. Pylori there and the non-steroidal anti-inflammatory drugs that are becoming the leading cause and risk factors for the deaths due to GI infections. These drugs are more harmful to the patients who had a history of peptic ulcer or have any other risk factors like increasing age and tobacco smoking, and alcohol consumption. Some other significant factors are stress and diet. Unhealthy eating habits like consuming spicy foods, carbonated beverages, and having much caffeine are also major risk factors for the ulcers. In the end, tobacco smoking and alcohol consumption worsen the condition by inhibiting the COX-2 receptor, which id cytoprotective and can help with the ulcers. These factors are contributing to the deaths of so many people with GI problems worldwide [22].

Helicobacter. Pylori infection is more common in adult as compared to children. This can be clarified by the birth associate impact or the total danger of contamination with age as the risk of affectability increases with age. If prosperity authorities wish to research the nature and degree of the relationship between way of life changes and Helicobacter pylori infection, a point by point investigation of the birth accomplice impact is important [23]. In this study, we discovered that the prevalence of $\mathrm{H}$. Pylori changes incredibly around the world. The connection between gender and $\mathrm{H}$. Pylori is disputable in numerous examinations; however, we dissect no such connection among gender and helicobacter pylori. Helicobacter pylori infection is a worldwide disease, and it does not resolve unexpectedly. More examination ought to be directed to investigate whether changes in Helicobacter pylori infection rates influence the burden of upper gastrointestinal ailments. Contrasted and develop the region, the rate of infection is higher in developing countries, and it appears to be that Helicobacter pylori can be viewed as another benchmark for the financial and wellbeing status of the network [24].

In this study, we found that PUD, especially $\mathrm{GU}$, had a higher recurrence rate of obese subjects than non-obese subjects. There was an important relationship between the risk of developing GU and obesity, but the organization was no longer critical when it came to fixing potentially disruptive factors. The incidence rates between the overweight and underweight groups were not significantly different in the Duodenal Ulcer, and there was no significant association. Also, the risk of acquiring a GU or DU did not indicate a positive affiliation with MHO. An association between PUD and obesity was investigated in several studies. Still, the results remained controversial Several studies have reported obesity as an independent risk factor for PUD However, some of these studies had limited diagnostic limitations based on self-reported PUD diagnostic questions. Therefore, very few PUD cases are likely to be ruled out, as they have less chance of visiting doctors for EGD or surgery. In six studies, only two studies in which participants were more likely to enter EGD. In addition, previous studies were limited by the small sample size, partial composition, and lack of data for the best possible candidates. Four of the six studies did not address the nature of Helicobacter pylori and the common use of NSAIDs or antiplatelet, which are wellknown causes of PUD [25].

Interestingly, a recent study using the Korea National Health and Nutrition Examination Survey showed conflicting results in this study. BMI was associated with PUD in men only, and that higher BMI reduced the risk of PUD in men [8]. This study was robust because it included a large number of studies (n $=23,015)$ and modified PUD dietary supplements. However, this was a cross-sectional study, with no information about Helicobacter pylori or the use of NSAIDs or antiplatelet, and the discovery of PUD was based on the report. These estimates can lead to different conclusions from people of the same country. The role of obesity in PUD is not well understood. In our study, the critical or linear level of the significant relationship between obesity and the risk of developing a PUD, assumed GU, was obtained (p-value 0. <001 in unadjusted model with a value of p0 -0.071 for Model 1 ), but the correlation disappeared after correction of lifestyle in Model 2 ( $\mathrm{p}$-value $=0.355)$. The significant association between obesity and PUD reported in other studies may be due to incomplete adjustment of these disruptive lifestyle factors. Also, the lack of a link between the risk of MHO and GU suggests that obesity itself, symbolized by BMI, was not a significant factor 
in PUD attacks, but lifestyle factors associated with metabolic syndrome could be a major risk factor for PUD risk [25].

The main purpose of this article was to identify the risk factors that lead to PUD detection, where there are common risk factors - the causes of PUD include $\mathrm{H}$ infection. Pylori and NSAIDs. Common risk factors include alcohol, smoking, cocaine, serious illness, physical problems, radiation treatment, and Crohn's disease. Among other things, $\mathrm{H}$. Pylori is considered the most common cause of $60 \%$ of gastritis and ulcers up to $50-75 \%$. A large sample of Danish research shows a significant contribution of Helicobacter pylorus as the most important risk factor in PUD, and the use of NSAIDs and immunosuppressive agents is associated with peptic ulcers. Genetic factors such as individuals with IL-1B-31C / $\mathrm{T}$ polymorphism may increase the risk of $\mathrm{H}$ infection. Pylori, and IL-1B-511-C / T and IL8-251T / Genetic polymorphism may be part of $\mathrm{H}$ related diseases. Pylori including GC or PUD. In a large expected group of male health workers, moderate obesity is associated with an increased risk of peptic ulcers, especially gastric ulcers and pylori- and malignant ulcers, indicating a significant increase in population or potentially significant work-related heat stress. There is also an inflammatory factor in which increased levels of TNF- $\alpha$ may play an important role in the pathogenesis of peptic ulcer in the presence of $\mathrm{H}$. Pylori.

On the other hand, a person's personality and symptoms are closely related to the emergence of PUD throughout life due to stress or exposure. Deteriorating personality risk poses a pathogen infection in a hospitalized diagnosis, in part due to exposure to unhealthy behaviours. Its effects are seen in ulcers associated with 'opio' and $\mathrm{H}$ pylori and in severe surgical conditions. Hostile behavior may also be associated with an increased risk of drug-induced ulcers. In a future study of a group of Danish people, stress increased the incidence of malignant lesions by influencing bad health habits. Compression had similar effects on wounds associated with $\mathrm{H}$ infection. Pylori and those that is not compatible with $\mathrm{H}$. Pylori or use of NSAIDs [26].

\section{CONCLUSION}

Overall studies and evidence suggest that several risk factors contribute to gastrointestinal disorders. PUD is specifically associated with H. Pylori bacteria, NSAIDs, Obesity, Smoking, Alcohol consumption, and unhealthy dietary habits. Both experimental and population-based studies showed that the risk of gastrointestinal disorders like ulcers is double in the people with these risk factors than the rest of patients. The people having a history of PUD and other determinants are more vulnerable to get a GI disorder. Bacteria that is involved (H.Pylori) caused $60 \%$ of the cases worldwide. This causes inflammation and weakens the immune system that makes the body more prone to disease. Studies have confirmed that one of the leading causes of PUD is Non-Steroidal Antiinflammatory drugs. Deficiency and toxicity of the drugs may lead to the inhibition of the enzymes that helps with the cure of gastrointestinal disorders. Our daily unhealthy dietary habits also lead to conditions like ulcers. Many studies showed that Spicy food and unfiltered water is becoming the leading cause, specifically among school-going children. Stress and obesity also play a vital role in worsening the disease. However, it was evident that the severity of the disease can be reduced easily by overcoming these risk factors. Healthy eating habits and living standards can help to reduce the symptoms up to $80 \%$. Eradication therapy is still the best choice for the people rather than having the NSAIDs to treat ulcers.

\section{Funding Source}

No funding sources

\section{Conflict of interest}

None to be declared

\section{Ethical approval}

Because it is a systematic review, no ethical consent is needed.

\section{REFERENCES}

1. Drini, M. (2017). Peptic ulcer disease and nonsteroidal anti-inflammatory drugs. Australian prescriber, 40(3), 91-95.

2. Leontiadis, G. I., Sreedharan, A., Dorward, S., Barton, P., Delaney, B., Howden, C. W., ... \& Moayyedi, P. (2007). Systematic reviews of the clinical effectiveness and cost-effectiveness of proton pump inhibitors in acute upper gastrointestinal bleeding. In NIHR Health Technology Assessment programme: Executive Summaries. 11(51),160-164.

3. Ramakrishnan, K., \& Salinas, R. C. (2007). Peptic ulcer disease. American family physician, 76(7), 1005-1012.

4. Serin, A., Tankurt, E., Şarkış, C., \& Simsek, I. (2015). The prevalence of Helicobacter pylori infection in patients with gastric and duodenal ulcers-a 10-year, single-centre experience. Przeglad Gastroenterologiczny, 10(3), 160.

5. Brown, L. M. (2000). Helicobacter pylori: epidemiology and routes of transmission. Epidemiologic reviews, 22(2), 283297.

6. Mynatt, R. P., Davis, G. A., \& Romanelli, F. (2009). Peptic ulcer disease: clinically relevant causes and treatments. Orthopedics, 32(2), 104.

7. Niv, Y. (2010). H. pylori/NSAID-Negative peptic ulcer-The mucin theory. Medical hypotheses, 75(5), 433-435. 
8. Najm, W.I. (2011). Peptic Ulcer Disease. Primary Care. 38(3):383-94.

9. Merck, M. (2006). Home Health Handbook for Patients \& Caregivers: Peptic ulcer Available:https://www.merckmanuals.com/home/di gestivedisorders/gastritis-and-peptic-ulcerdisease/pepticulcer-disease. Accessed 19 August 2018.

10. Mahan, L. K., Escott-Stump, S., \& Raymond, J. L. (2013). Krause dietoterapia. Amsterdam: Elsevier.

11. Prabhu, V., \& Shivani, A. (2014). An overview of history, pathogenesis and treatment of perforated peptic ulcer disease with evaluation of prognostic scoring in adults. Annals of medical and health sciences research, 4(1), 22-29.

12. Van der Hulst, R. W. M., \& Tytgat, G. N. J. (1996). Helicobacter pylori and peptic ulcer disease. Scandinavian Journal of Gastroenterology, 31(sup220), 10-18.

13. Malmi, H. (2018). Peptic ulcer disease-incidence, associated morbidity and mortality. University of Helsinki.

14. Bhatia, V., \& Tandon, R. K. (2005). Stress and the gastrointestinal tract. Journal of gastroenterology and hepatology, 20(3), 332-339.

15. Rosenstock, S., Jørgensen, T., Bonnevie, O., \& Andersen, L. (2003). Risk factors for peptic ulcer disease: a population based prospective cohort study comprising 2416 Danish adults. Gut, 52(2), 186-193.

16. Lee, S. P., Sung, I. K., Kim, J. H., Lee, S. Y., Park, H. S., \& Shim, C. S. (2017). Risk factors for the presence of symptoms in peptic ulcer disease. Clinical endoscopy, 50(6), 578.

17. Søreide, K., Thorsen, K., Harrison, E. M., Bingener, J., Møller, M. H., Ohene-Yeboah, M., \& Søreide, J. A. (2015). Perforated peptic ulcer. The Lancet, 386(10000), 1288-1298.

18. Qadir, M. I., \& Saba, M. (2019). Apprehension of facts of causes and prevention of the peptic ulcer in Bahauddin Zakariya University, Multan, Pakistan.

19. Deding, U., Ejlskov, L., Grabas, M. P. K., Nielsen, B. J., Torp-Pedersen, C., \& Bøggild, H. (2016). Perceived stress as a risk factor for peptic ulcers: a register-based cohort study. BMC gastroenterology, 16(1), 140.
20. Lee, Y. B., Yu, J., Choi, H. H., Jeon, B. S., Kim, H. K., Kim, S. W., ... \& Chae, H. S. (2017). The association between peptic ulcer diseases and mental health problems: A population-based study: a STROBE compliant article. Medicine, 96(34).

21. Drini, M. (2017). Peptic ulcer disease and nonsteroidal anti-inflammatory drugs. Australian prescriber, 40(3), 91.

22. Mustafa, M., Menon, J., Muiandy, R.K., Fredie, R., Sein, M.M., Fariz. (2015). A. Risk factors, diagnosis, and management of peptic ulcer disease. Journal of Dental and Medical Sciences, 14(7),406.

23. Darwin, E., Murni, A. W., \& Nurdin, A. E. (2017). The effect of psychological stress on mucosal IL-6 and Helicobacter pylori activity in functional dyspepsia. Acta Medica Indonesiana,49(2), 99104.

24. Zamani, M., Ebrahimtabar, F., Zamani, V., Miller, W. H., Alizadeh-Navaei, R., Shokri-Shirvani, J., \& Derakhshan, M. H. (2018). Systematic review with meta-analysis: the worldwide prevalence of Helicobacter pylori infection. Alimentary pharmacology \& therapeutics, 47(7), 868-876.

25. Pyo, J. H., Lee, H., Kim, J. E., Choi, Y. H., Kim, T. J., Min, Y. W., ... \& Kim, K. (2019). Obesity and risk of peptic ulcer disease: a large-scale health check-up cohort study. Nutrients, 11(6), 1288.

26. Asali, A. M., Alghamdi, M. A., Fallatah, S. A., Alholaily, W. A., Aldandan, R. G., Alnosair, A. H., ... \& Alharbi, R. A. (2018). Risk factors leading to peptic ulcer disease: systematic review in literature. International Journal of Community Medicine Public Health, 5, 4617-24.

27. Lee, S. P., Sung, I. K., Kim, J. H., Lee, S. Y., Park, H. S., \& Shim, C. S. (2015). The effect of emotional stress and depression on the prevalence of digestive diseases. Journal of neurogastroenterology and motility, 21(2), 273.

28. Lee, Y. B., Yu, J., Choi, H. H., Jeon, B. S., Kim, H. K., Kim, S. W., ... \& Chae, H. S. (2017). The association between peptic ulcer diseases and mental health problems: A population-based study: a STROBE compliant article. Medicine, 96(34). 